\title{
LOW-VALUE NICKEL RESISTORS ELECTROLESS-PLATED ON "IMST" SUBSTRATE FOR POWER HYBRID ICs
}

\author{
N. MIURA, Y. FUURA and A. KAZAMI \\ Tokyo IC Co., Ltd. \\ (a Division of Tokyo Sanyo Electric Co., Ltd.) \\ 414-1 Omamacho, Yamadagun, Gummaken, Japan
}

\begin{abstract}
This paper describes a new resistor formation technique, characterized by the use of our unique hybrid IC substrate (IMST substrate) and the electroless nickel plating on it.

The evaluation of various electroless nickel plating baths to deposit nickel alloy with a different composition for each is included. The resistor properties of the nickel film from a selected bath are showed. The plating conditions affecting the resistance are discussed. Finally, the application to the built-in emitter resistors of the IMST audio power hybrid IC is presented.
\end{abstract}

\section{INTRODUCTION}

Power-transistor circuits usually require low-value resistors in series with the emitter of the powertransistor for the purpose of circuit protection and stabilization. Metal film cement resistors are generally used for them. Power thick film hybrid ICs using ceramic substrate may rarely have built-in low-value power resistors. Their materials are usually screenprinting conductive pastes such as Au-Pt paste. These materials are high cost and may be difficult to control the resistance.

Our hybrid IC system is a unique one designated as IMST (Insulated Metal Substrate Technology). ${ }^{1-3}$ This This substrate, as its cross-sectional view are shown in Figure 1, consists of three kinds of material: aluminium, epoxy and copper. The epoxy will limit the processing temperature below $300^{\circ} \mathrm{C}$ and does not permit to use such cermet pastes as Au-Pt paste, which must he processed at a higher temperature over $600^{\circ} \mathrm{C}$.

We were looking for a proper system for low-value power resistors, compatible with conventional IMST system and also of low cost and high precision. As its proper system, electroless nickel plating was considered to be applicable. Electroless plated nickel contains such an impurity atom as phosphorus, boron and cobalt, and consequently exhibits a higher resistivity than pure metal. Electroless nickel-phosphorus alloy film has been used as a resistive material of metal film cermet resistors.
We took up three kinds of electroless nickel plating bath and selected a proper one. At the same time, a selective electroless plating technique was developed to form a resistor pattern. This new resistor system has been successfully developed and applied to 10 per cent of the total IMST hybrid IC production.

This paper is divided into the following:

Evaluation of electroless nickel plating bath

Properties of nickel alloy resistors containing 8 to $10 \%$ phosphorus

Control of resistance

Application

Conclusion and summary

\section{EVALUATION OF ELECTROLESS NICKEL PLATING BATH}

Three kinds of standard commercial electroless plating bath to deposit nickel alloy with a different composition of co-deposited metal and its content were taken up and investigated as to their propriety as low-value power resistors. A test piece using the IMST substrate for the evaluation of these baths is shown in Figure 1. It should be noticed that nickel film is coated on both epoxy layer and copper conductor, having a resistor pattern. The copper conductor plays a role of the terminal of nickel resistors. The test piece was prepared by the following procedure: 


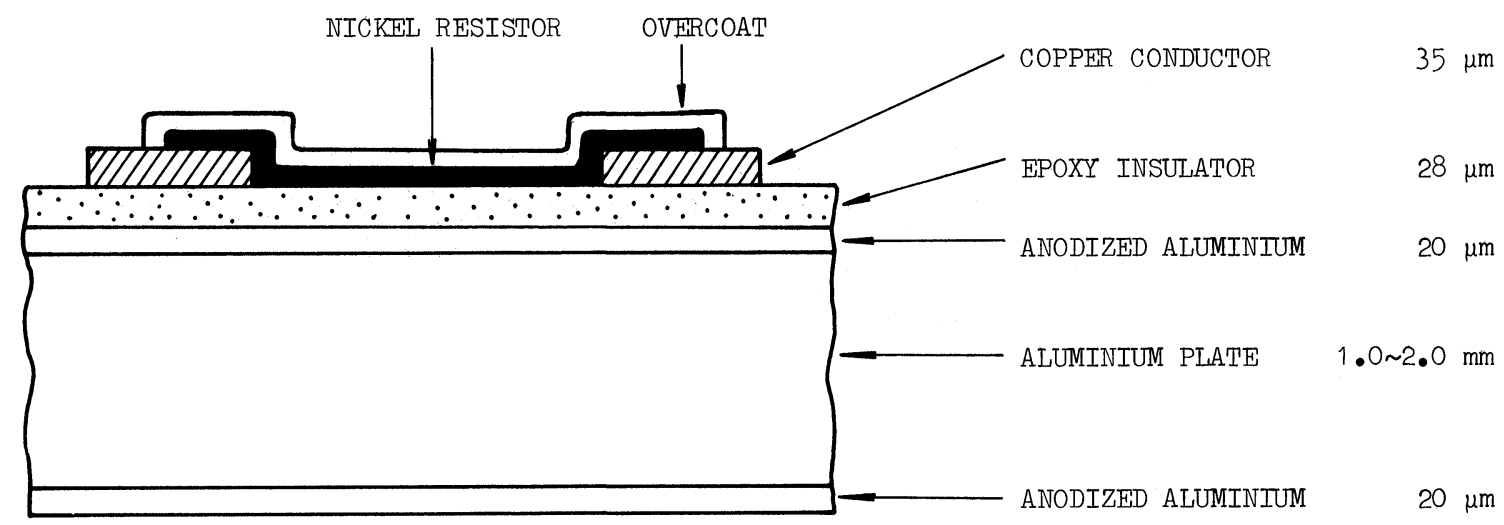

A. CROSS-SECTIONAL VIEW OF IMST SUBSTRATE

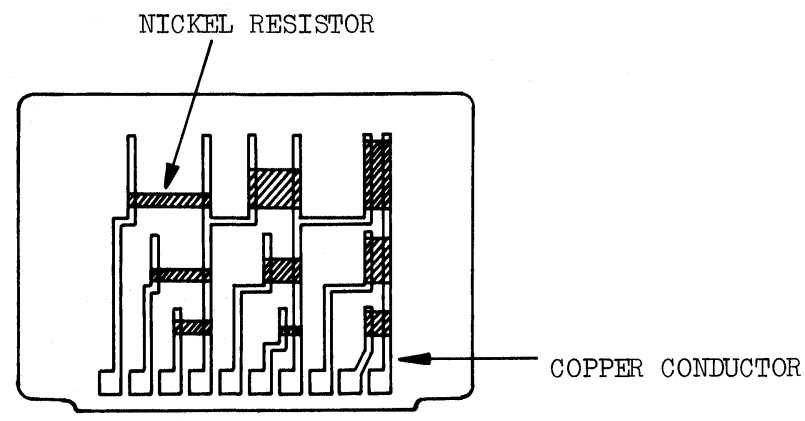

\section{B. TEST PIECE USING IMST SUBSTRATE}

FIGURE 1 The structure and configuration of test piece using IMST substrate.

Etch copper to make a conductor pattern

Print a plating resist

Deposit catalyst

Water rinse

Accelerator dip

Water rinse

Electroless plate

Water rinse

Remove a plating resist

After this, the test piece was subjected to heat treatment of $200^{\circ} \mathrm{C}$ for 6 hours in air atmosphere, which condition was temporarily set to the curing condition of resin-based carbon resistive paste, the resistive material in the conventional IMST system. As a result, this condition has proved to be proper by further investigation, as described later, and has been adopted as the process standard. An overcoat was screen printed on the test piece. And then these test pieces were subjected to TCR measurement and temperature cycling test.

Table I summarizes the properties and test result of each bath. This preliminary investigation revealed that all of the baths were basically acceptable excepting a point of TCR. Bath B and C had a too large TCR. Bath A had a relatively low one and was exclusively selected for further evaluation. The TCR seems to be closely related to impurity content. Each of convenient adhesion tests such as bending and filing could not cause the peeling of the nickel film from epoxy layer and copper conductor. The good adhesion on epoxy layer may be attributed to its proper surface roughness transferred from the copper foil, which is the same type as used in printed circuit boards.

The selected bath is a most typical type and has the following formulation:

Sodium hypophosphite $2.5 \%$

Nickel chloride $\quad 1.7 \%$

Complexant $\quad 1.5 \%$

Succinic acid $\quad 0.8 \%$

Glycol acid $\quad 0.7 \%$

Additive (A) $\quad 0.2 \%$

Additive (B) $\quad 0.02 \%$ 
TABLE I

Properties of electroless nickel plating baths.

\begin{tabular}{llll}
\hline Designation & Bath A & Bath B & Bath C \\
\hline Co-deposited metal and its content & $\mathrm{P}: 8-10 \%$ & $\mathrm{P}: 3 \%$ & $\mathrm{~B}: 1 \%$ \\
p.H & 5.8 & 9.0 & 7.0 \\
Plating time & $90^{\circ} \mathrm{C}$ & $25^{\circ} \mathrm{C}$ & $60^{\circ} \mathrm{C}$ \\
Plating temperature & $4 \mathrm{~min}$ & $20 \mathrm{~min}$ & $7 \mathrm{~min}$ \\
Film thickness & $2.5 \mu \mathrm{m}$ & $2.0 \mu \mathrm{m}$ & $2.8 \mu \mathrm{m}$ \\
Sheet resistivity & $0.70 \Omega / \square$ & $0.07 \Omega / \square$ & $0.07 \Omega / \square$ \\
TCR $+25^{\circ} \mathrm{C}$ to $-200{ }^{\circ} \mathrm{C}$ & $+450 \mathrm{ppm} /{ }^{\circ} \mathrm{C}$ & $+1600 \mathrm{ppm} /{ }^{\circ} \mathrm{C}$ & $+2600 \mathrm{ppm} /{ }^{\circ} \mathrm{C}$ \\
Temperature cycling, $\% \mathrm{R}$ & $<0.5 \%$ & $<0.5 \%$ & $<0.5 \%$ \\
$-40^{\circ} \mathrm{C}$ to $+150^{\circ} \mathrm{C}, 100$ cycles & & & \\
\hline
\end{tabular}

The vendor of these baths: Okuno Chemical Industries Co., Ltd.

\section{PRCPERTIES OF NICKEL ALLOY RESISTORS CONTAINING 8 TO 10\% PHOSPHORUS}

It is well known that heat treatment will greatly affect the properties of electroless nickel-phosphorus alloy. Usually it will bring an increase in hardness and a decrease in resistivity. Therefore, the determination of proper heat treatment condition was a important problem to be solved first of all.

Maximum heat treatment in the conventional IMST fabrication processes is the curing of resin-based carbon resistive paste, $200^{\circ} \mathrm{C}$ for 6 hours. The other processes are carried out below $200^{\circ} \mathrm{C}$ and moreover in a relatively short time. For this reason, it was expected that this curing would at the same time provide an adequate annealing effect to the nickel alloy, eliminating an additional heat treatment process. As shown in Figure 2, the resistance of as-plated nickel

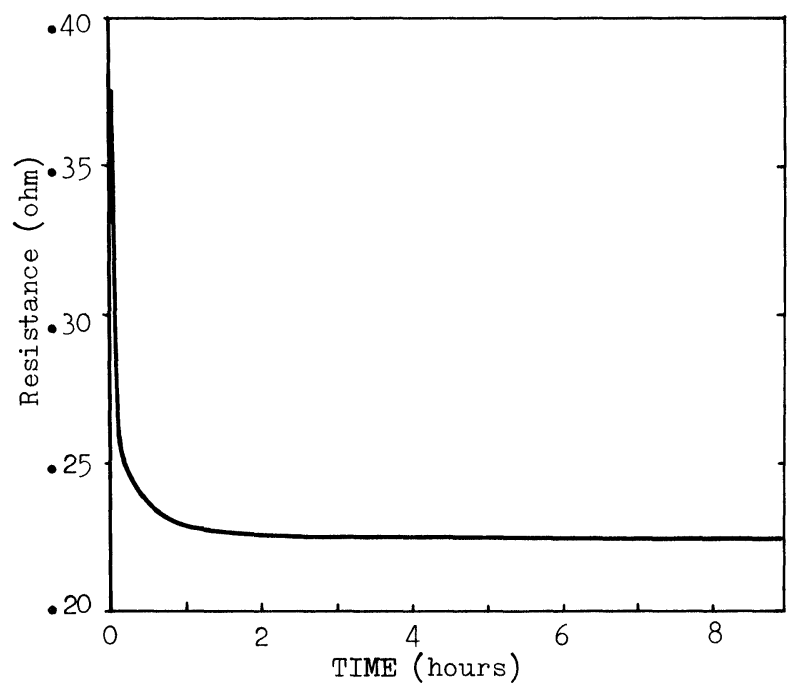

FIGURE 2 The resistance change of as-plated nickel alloy on heat treatment at $200^{\circ} \mathrm{C}$. resistors abruptly decreased in a early stage of heat treatment at $200^{\circ} \mathrm{C}$ and reached almost the final value in 4 hours. This saturation indicated heat treatment of $200^{\circ} \mathrm{C}$ for 6 hours would be enough to get the thermally stable resistor, in consideration of a relatively low operation temperature of the resistor.

Different from the cement resistors, the nickel resistors are able to dissipate their generated heat through aluminium plate beneath into a heat sink, with a lower thermal resistance. Consequently the temperature rise will be restricted far below. Thermal design may be practically made for the resistors to operate below 120 to $150^{\circ} \mathrm{C}$.

TABLE II

Life test results of $\mathrm{Ni}-\mathrm{P}$ alloy resistors.

\begin{tabular}{lc}
\hline Test & Resistance change \\
\hline High temperature storage & \\
$1000 \mathrm{hr}$ at $150^{\circ} \mathrm{C}$ & $-2.0 \%$ \\
$1000 \mathrm{hr}$ at $125^{\circ} \mathrm{C}$ & $-0.5 \%$ \\
Resistance to humidity & $-0.3 \%$ \\
$1000 \mathrm{hr}$ at $85^{\circ} \mathrm{C}, 85 \%$ & $-0.7 \%$ \\
Load life & \\
$0.52 \mathrm{~W} / \mathrm{mm}^{2}, \mathrm{Tc}=105^{\circ} \mathrm{C}$ & $-0.4 \%$ \\
Temperature cycling & $< \pm 0.4 \%$ \\
$-40^{\circ} \mathrm{C}$ to $+150^{\circ} \mathrm{C}, 1000 \mathrm{cycles}$ & \\
Short time load life & \\
\hline
\end{tabular}

Resistor: $9 \mathrm{~mm}$ wide, $1.7 \mathrm{~mm}$ long with a typical resistance of $0.22 \mathrm{ohm}$.

Short time load life: To supply a rectified $50 \mathrm{c} / \mathrm{s} \mathrm{AC} \mathrm{with} \mathrm{a}$ peak of 18 ampere.

To confirm the practical effectiveness of the heat treatment condition, $200^{\circ} \mathrm{C}$ for 6 hours, the nickel resistors processed through all the IMST fabrication processes were subjected to the various tests, required for low-value power resistors of audio power amplifiers. The results are shown in Table II and Figure 3. 

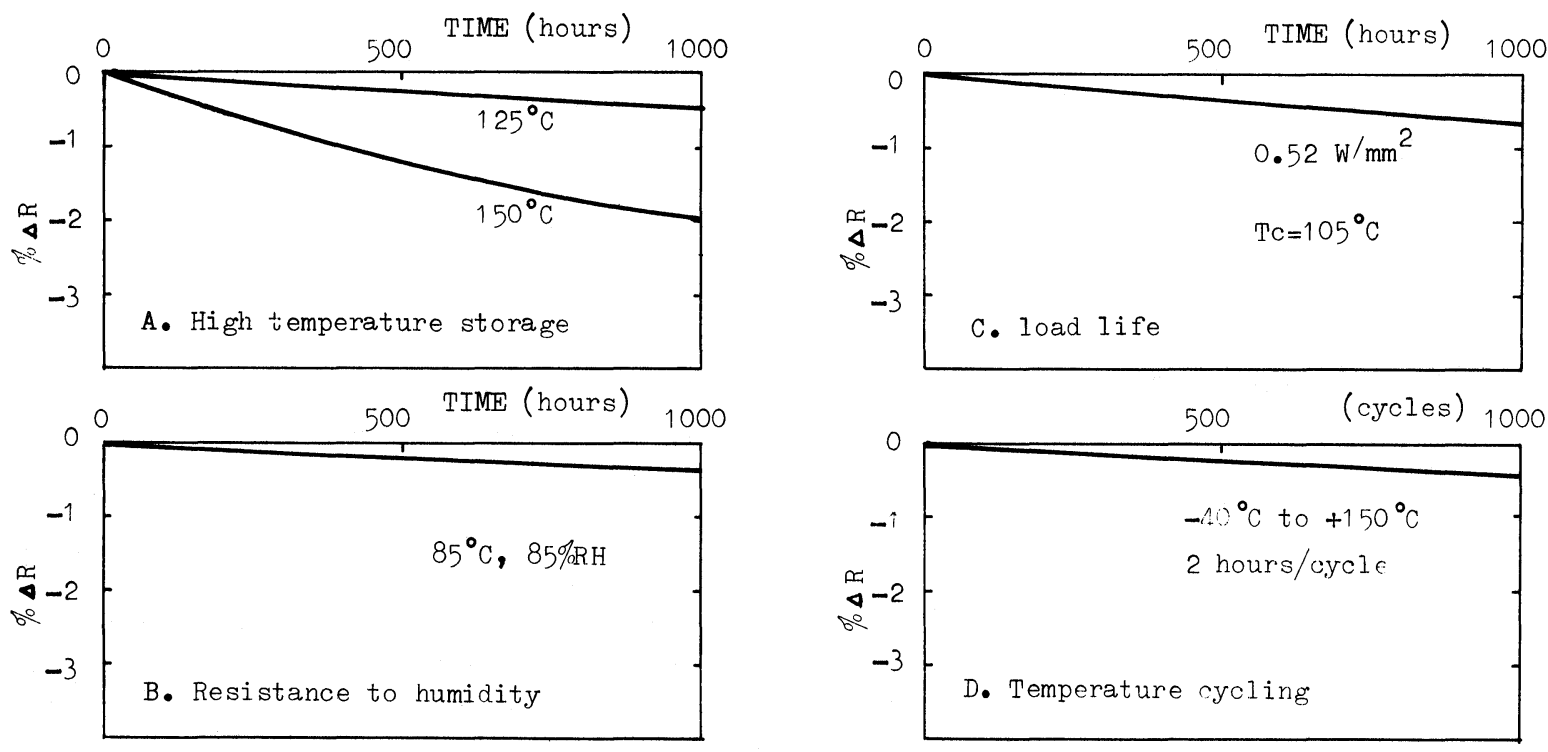

FIGURE 3 Life test results of Ni-P alloy resistors.

As the results show, the nickel resistors produced by such a method were quite reliable. The resistance change related to thermal degradation was very low, as was expected. The excellent humidity resistance may be attributed to the high corrosion resistance of the nickelphosphorus alloy. Thus, the curing condition of the resistive paste has proved to perform the function of the annealing enough to provide these excellent characteristics.

\section{CONTROL OF RESISTANCE}

The resistance of as-plated nickel film will decrease by about $40 \%$ after the curing of carbon resistors, as shown in Figure 2. A practical control method of the resistance is to occasionally monitor the resistance of the as-plated film, in consideration of the reduction rate. If any adjustment is needed, it is made by changing the plating time, keeping the other condition as constant as possible. The final resistance is a reciprocal function of the plating time, as shown in Figure 4, in accordance with the fact that the film thickness is directly proportional to the plating time (see Figure 5). This normal relation implies that any film in the thickness range examined will have the same structure and physical property. These characteristics will enable us to make the resistance control simple and also to get a wide sheet resistivity range.

The other main plating conditions are bath

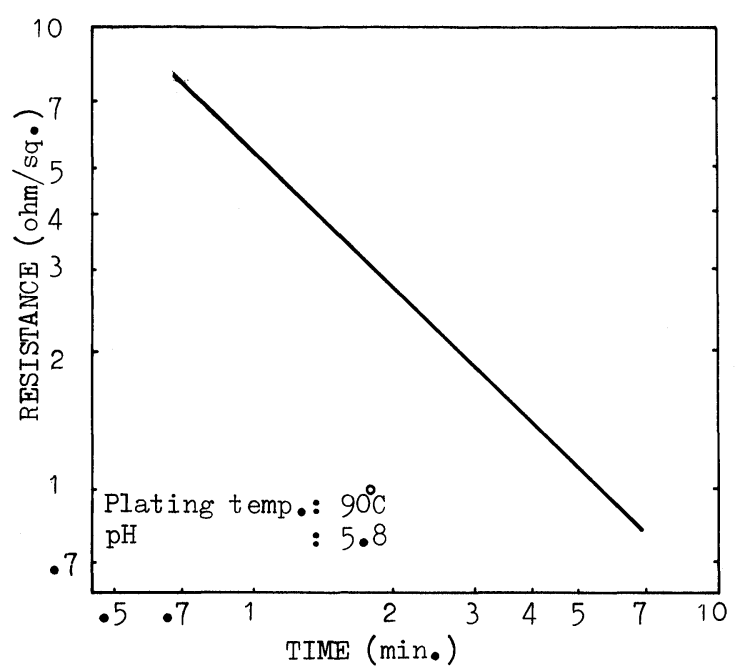

FIGURE 4 Resistance vs. plating time.

temperature, $\mathrm{pH}$ and rocking rate. The resistance decreases with the increasing temperature, as shown in Figure 6. The temperature effect is so great that our plating system is designed to keep the temperature fluctuation within $\pm 1{ }^{\circ} \mathrm{C}$. The resistance decreases with the increasing $\mathrm{pH}$, as shown in Figure 7. Since the $\mathrm{pH}$ gradually drops with the consumption of nickel ion, it is a point how to keep it constant. The rocking rate is related to the relative liquid velocity over the article to be plated. To increase the rocking rate accelerates the 


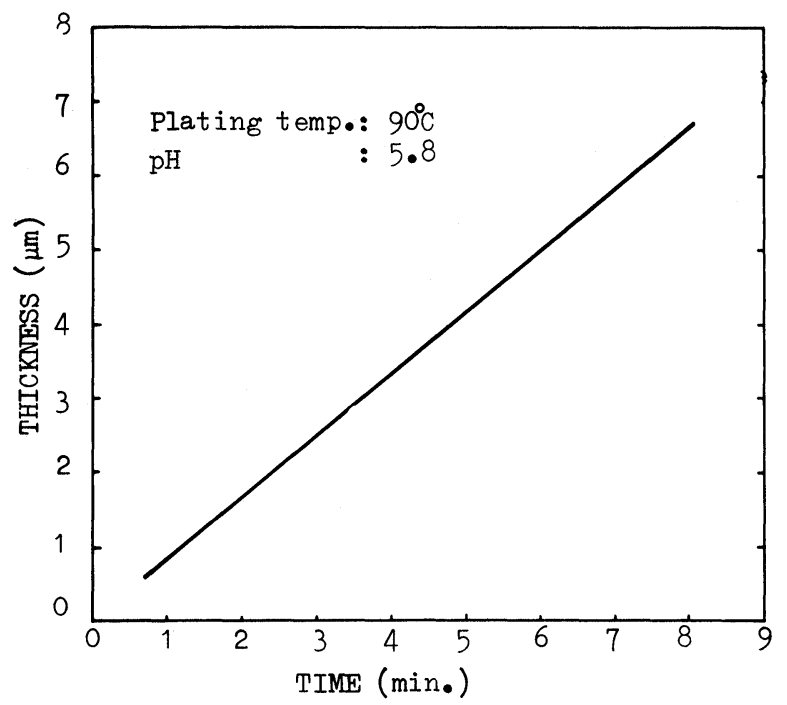

FIGURE 5 Film thickness vs. plating time.

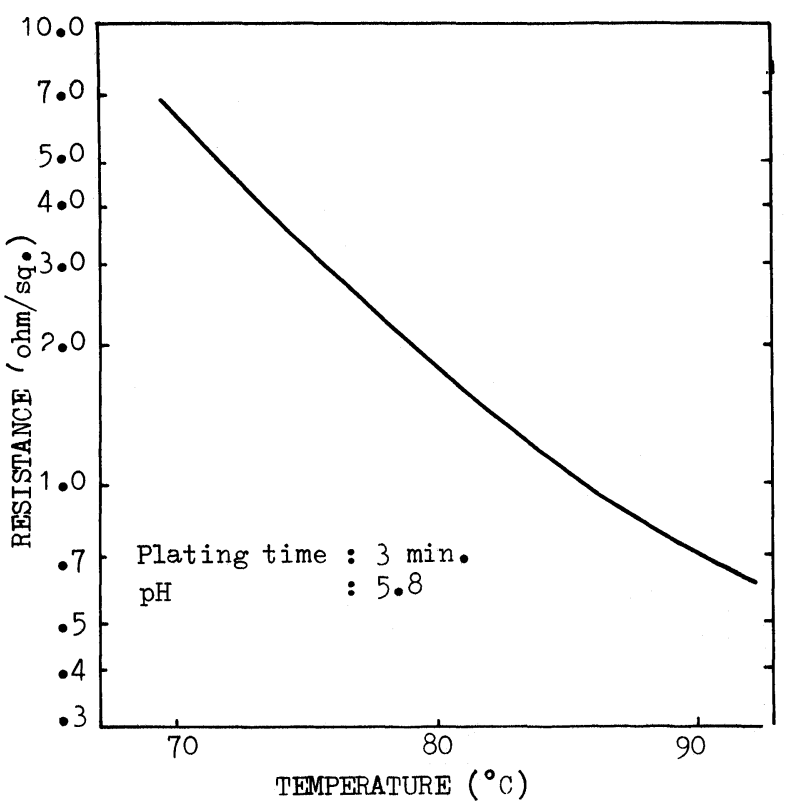

FIGURE 6 Resistance vs. plating temperature.

chemical reaction, leading to the decreased resistance (see Figure 8). At a low rocking rate, the resistance values show larger variations. This may be caused by the disorderly stirring of the solution.

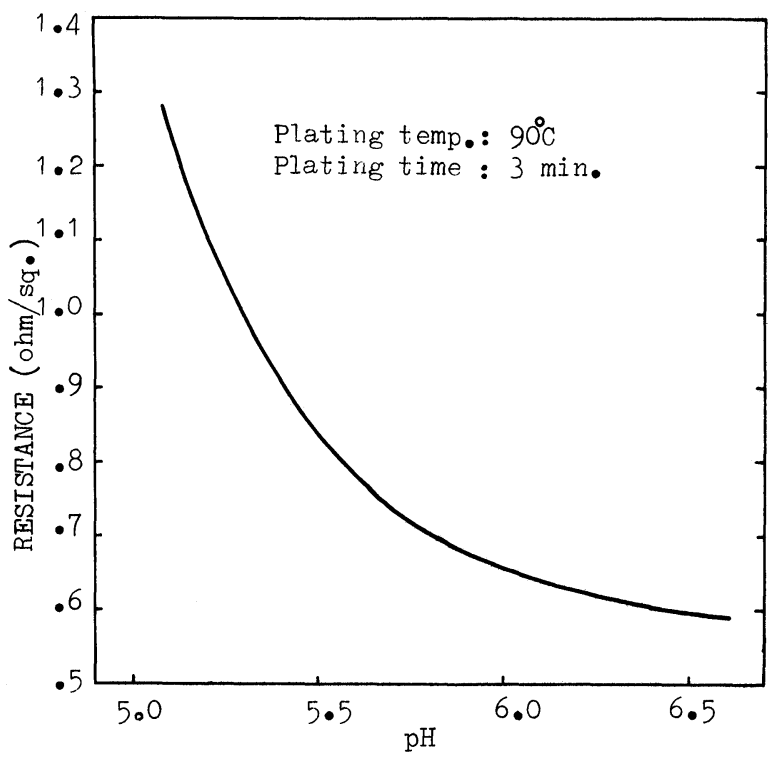

FIGURE 7 Resistance vs. pH.

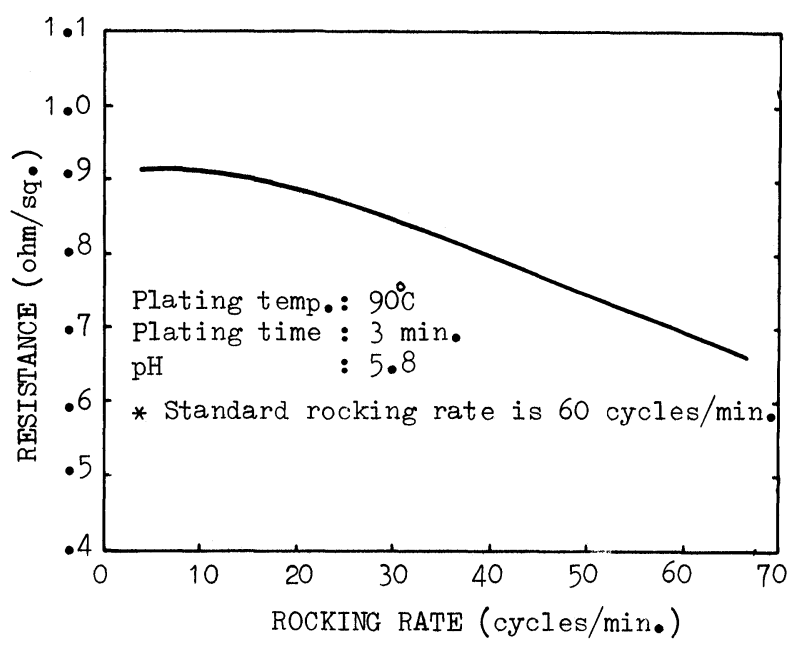

FIGURE 8 Resistance vs. rocking rate.

The resistors obtained from the standard plating condition, $90^{\circ} \mathrm{C}$ for 3 minutes at $\mathrm{pH}=5.8$, will have a sheet resistivity of $0.70 \mathrm{ohm}$ per square with the film thickness $2.5 \mu \mathrm{m}$. The percentage standard deviation of the resistance values per a plating rack, which could contain 300 to 420 IC substrates in a strip form, is 2.5 to $3.0 \%$ and the deviation of the mean between the rack will be less than $5 \%$, depending on the control method. The resistance tolerance of $\pm 15 \%$ will be attained without trimming. 


\section{APPLICATION}

The nickel resistor system has been applied to some of IMST audio power hybrid ICs. As an example,

STK1050 will be described below. The STK1050 is a D.P.P. IC (Darlington Power Pack IC), which contains a output stage with a Darlington pure complementary circuit for a AF 50W amplifier. The equivalent circuit is shown in Figure 9. The two emitter resistors with

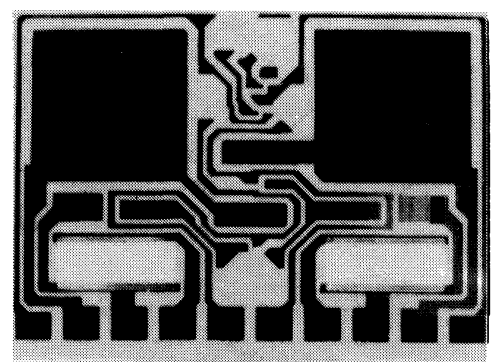

4500

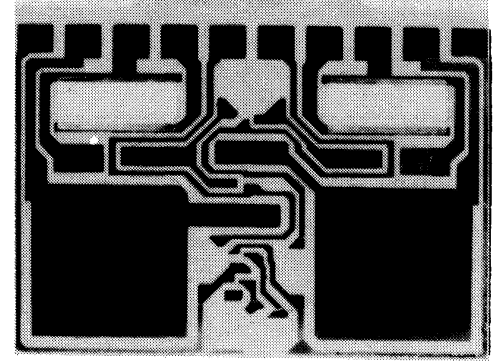

A. IMST substrate with nickel resistors.

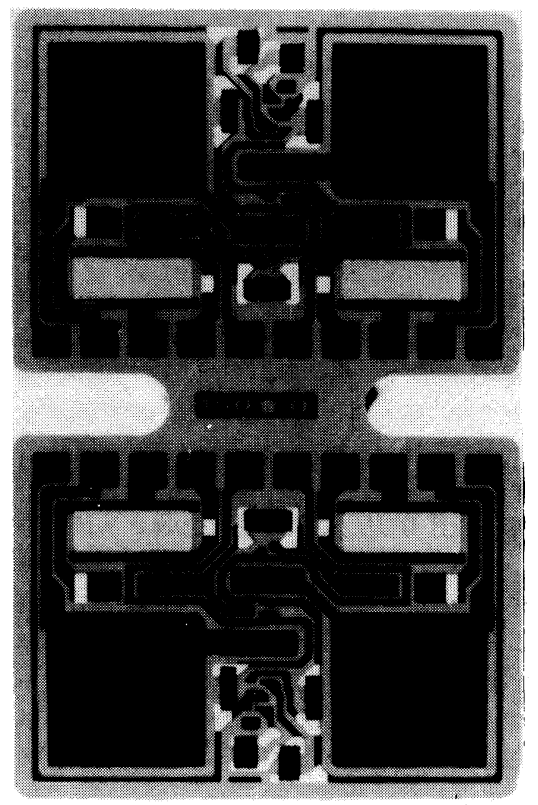

B. Screen printing of carbon resistors.

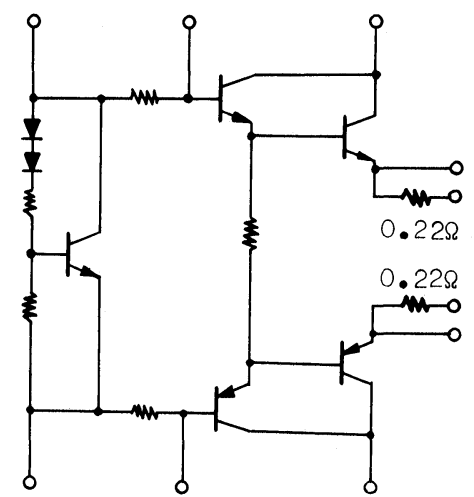

FIGURE 9 The equivalent circuit of STK1050.
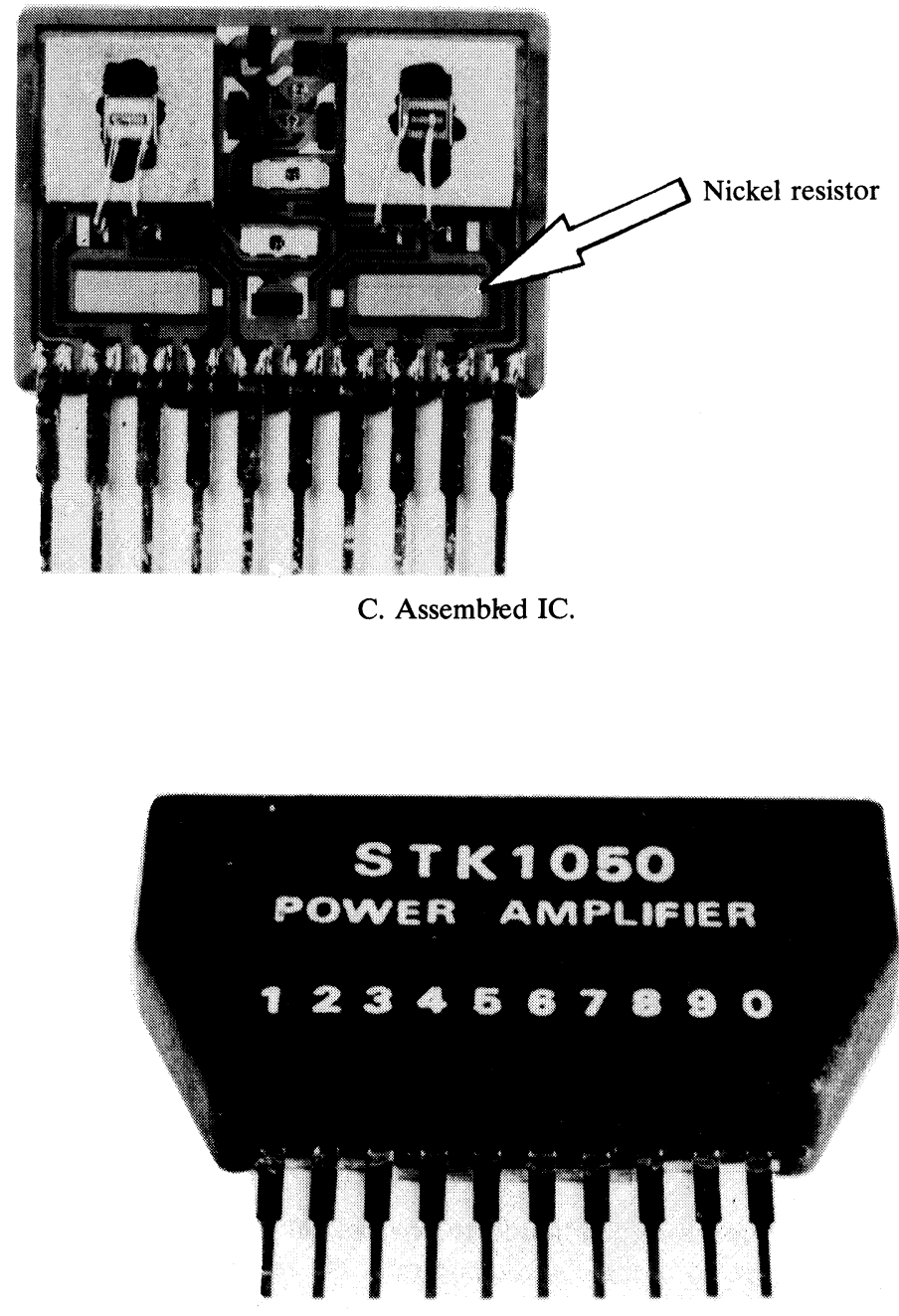

D. Completed IC.

FIGURE 10 The fabrication processes of STK1050. 
$0.22 \mathrm{ohm}$ are made by this system. The fabrication processes are illustrated in Figure 10. First, the emitter resistors of nickel alloy are electroless plated and then conventional IMST processes succeed. The plating process is basically the same as described previously in the section of bath evaluation. In Table III shown are the specifications of the STK1050. The building-in of the emitter resistors has brought such advantages as the design flexibility of printed circuit board and the availability of a relatively low distortion at a high frequency range, of course including the reduction of total cost.

TABLE III

Specifications of STK1050

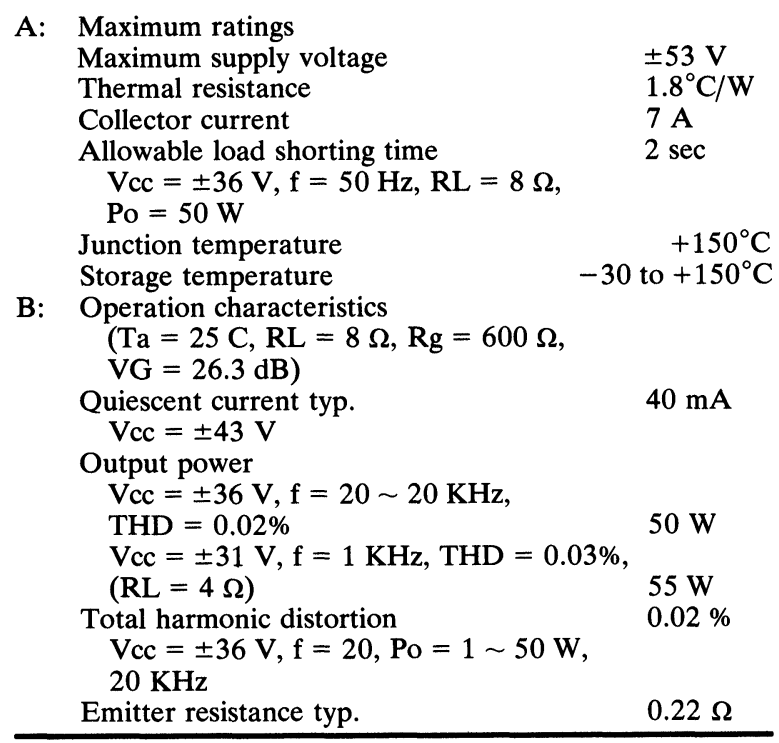

\section{CONCLUSION AND SUMMARY}

1) A new resistor formation technique to electroless plate nickel alloy on the IMST substrate has proved to be effective for low-value power resistors, and has been successfully applied to the emitter resistors of the IMST audio power hybrid IC.

2) A bath to deposit the nickel alloy containing 8 to $10 \%$ phosphorus was most suitable among three kinds of standard commercial one examined.

3) Heat treatment of $200^{\circ} \mathrm{C}$ for 6 hours in air was enough to offer the excellent resistor properties.

4) The resistors obtained from the standard plating condition had a sheet resistivity of $0.7 \mathrm{ohm}$ per square with a film thickness of $2.5 \mu \mathrm{m}$. ${ }^{*}$ Standard plating condition: $90^{\circ} \mathrm{C}, 3 \mathrm{~min}, \mathrm{pH}=5.8$.

5) The percentage standard deviation of resistance values was 2.5 to $3.0 \%$ per a plating rack which contained 300 to 420 IC substrates. The variation of the mean between the racks was less $3 \%$, providing the resistance tolerance of $\pm 15 \%$ without trimming.

\section{REFERENCES}

1. N. Miura, Y. Fuura and A. Kazami, High Power I.C. on Insulated Metal Substrate, Proceedings of Hybrid Microelectronics Symposium, 379-386 (1969).

2. N. Miura, Y. Fuura and A. Kazami, High Power Hybrid IC on Insulated Metal Substrates, Proceedings of the 1st Conference on Solid State Devices, Tokyo, 211-217 (1969).

3. N. Miura, Y. Fuura and A. Kazami, Insulated Metal Substrates for Power Hybrid ICs, Proceedings of International Microelectronics Symposium, pp 222-229 (1977). 

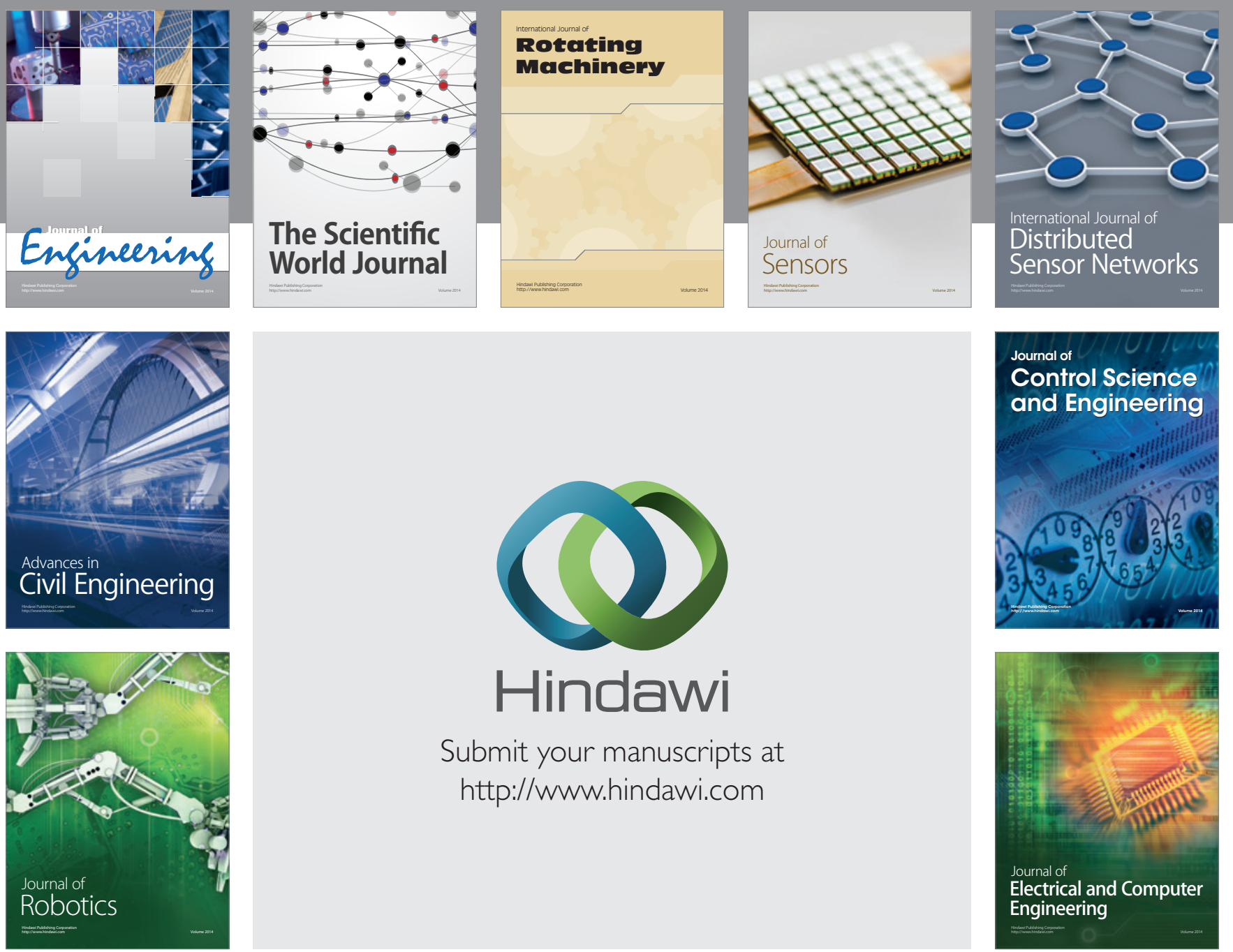

Submit your manuscripts at

http://www.hindawi.com
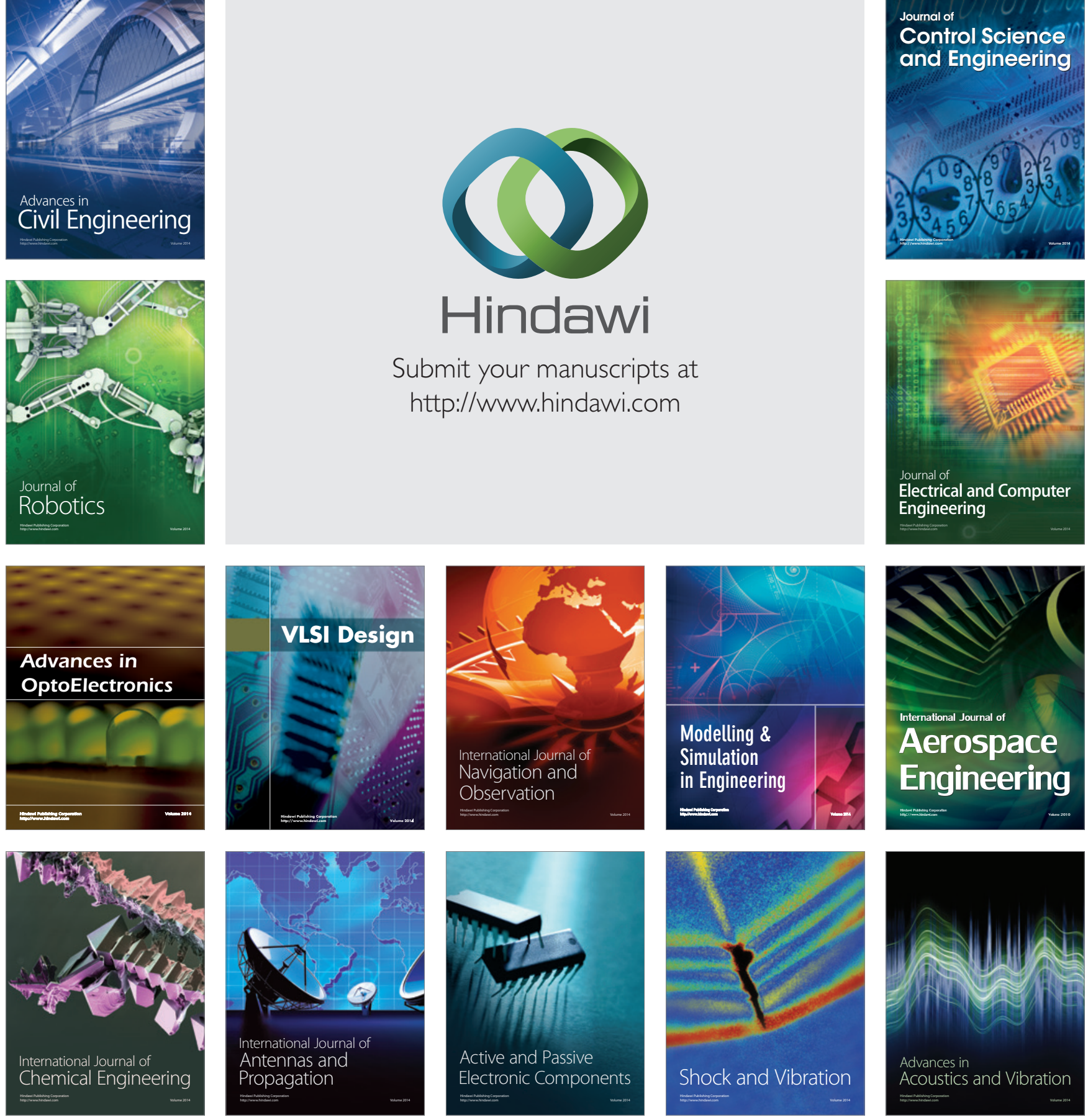